American Journal of Environmental Sciences 5 (4): 508-516, 2009

ISSN 1553-345X

(C) 2009 Science Publications

\title{
Adsorption Study of Several Hydrophobic Organic Contaminants on an Aquifer Material
}

\author{
Barbara Ruffino and Mariachiara Zanetti \\ DITAG-Department of Land, Environment and Geo-Engineering, \\ Politecnico di Torino, \\ Corso Duca Degli Abruzzi, 24-10129 Torino, Italy
}

\begin{abstract}
Problem statement: Aim of the present research was to determine coefficient of partition $\mathrm{K}_{\mathrm{D}}$ between soil and groundwater for five hydrophobic organic pollutants (benzene, chlorobenzene, trichloroethylene-TCE, perchloroethylene-PCE and toluene) in an Italian aquifer material characterized by a low organic carbon content $\left(f_{O C}=0.00262\right)$ by means of laboratory batch tests. Initial aqueous concentrations (quite different among the five compounds) were representative of the pollution level of considered site. Approach: Adsorption data for five afore mentioned compounds were obtained by means of laboratory tests: Multi-contaminant adsorption tests were performed putting in contact $50 \mathrm{~g}$ of dried soil together with $200 \mathrm{~mL}$ of a contaminant solution for $72 \mathrm{~h}$ in order to achieve the equilibrium. After $72 \mathrm{~h}$, supernatant was then analyzed by means of headspace gaschromatography providing the equilibrium concentration of the contaminants of interest in liquid phase. The concentration of contaminants of interest in solid phase (adsorbent) was determined taking advantage of a mass balance performed on each contaminant. Results: Results showed that both linear isotherm (in form of Henry isotherm) and Freundlich isotherm were able to fit experimental points for benzene, chlorobenzene, TCE and PCE in a satisfactory way; as for these four contaminants, PCE is more strongly adsorbed than TCE and TCE, in its turn, is more strongly adsorbed than benzene and chlorobenzene. On the other hand, Langmuir model appeared to be the most suitable in fitting toluene experimental points. The comparison between real distribution coefficient $\mathrm{K}_{\mathrm{D}}$ obtained fitting experimental points with an Henry-type isotherm and $\mathrm{K}_{\mathrm{D}}$ obtained on grounds of a theoretical model, like Linear Free Energy Relationships (LFER-based model), showed that LFER model uniformly underestimate the sorption process over whole concentration range, with the only exception of toluene. In case of toluene, LFER-based model fitted the sorption data very well; besides, Henry-type $\mathrm{K}_{\mathrm{D}}$ is very close to that calculated from LFER correlation over the tested concentration range: Difference between two $\mathrm{K}_{\mathrm{D}}$ values is the smallest among five considered contaminants $\left(\mathrm{K}_{\mathrm{D}}\right.$ toluene theoretical LFER $=0.520 \mathrm{~L} \mathrm{~kg}^{-1} ; \mathrm{K}_{\mathrm{D}}$ toluene experimental $\left.=0.465 \mathrm{~L} \mathrm{~kg}^{-1}\right)$. Conclusion: The important practical implication of results came from batch tests was that the calculation of $\mathrm{K}_{\mathrm{D}}$ based on theoretical models, like LFER, may give a wrong sorption estimation in some aquifers with a relatively low $\mathrm{f}_{\mathrm{OC}}$ content.
\end{abstract}

Key words: Hydrophobic Organic Contaminants (HOCs), sorption isotherms, low organic carbon content, LFER model

\section{INTRODUCTION}

The distribution of the Hydrophobic Organic Compounds (HOCs) between soil/sediments and an aqueous phase is of central importance in modeling the transport and fate of such substances in underground. Bioavailability and environmental transport of chemicals in soil-water systems are controlled by their adsorption properties.
The adsorption capacity for any organic pollutant is believed to depend upon three main factors: (a) the sorbate characteristics like polarity, hydrophobicity, molecular size, aqueous solubility, functional groups present and branching; (b) the characteristics of the liquid phase like $\mathrm{pH}$, temperature and ionic strength; (c) the sorbent characteristics like surface area, organic matter, mineral surfaces, pore size ${ }^{[1-5]}$.

Corresponding Author: Barbara Ruffino, DITAG-Department of Land, Environment and Geo-Engineering,

Politecnico di Torino, Corso Duca Degli Abruzzi, 24-10129 Torino, Italy 
The equilibrium distribution of the studied solutes is usually described by some specific form of the general equation:

$q=f\left(C_{e}\right)$

Where:

$\mathrm{q}=$ The amount of the compound adsorbed by the soil/sediment, $\mathrm{mg} \mathrm{kg}^{-1}$

$\mathrm{C}_{\mathrm{e}}=$ The concentration of the compound remaining in equilibrium in the solution, $\mathrm{mg} \mathrm{L}^{-1}$

Depending on the type of interactions, the adsorption Eq. 1 can take on various specific forms ${ }^{[6]}$. The most simple form is described by the Henry isotherm, a linear model of partition characterized by a single parameter, the coefficient of distribution between the substance bound to the soil and the substance in the dissolved form, $\mathrm{K}_{\mathrm{d}}, \mathrm{L} \mathrm{kg}^{-1}$ of sediment:

$\mathrm{q}=\mathrm{K}_{\mathrm{d}} \cdot \mathrm{C}_{\mathrm{e}}$

The partition model regards the natural organic matter in the soil as a three dimensional macromolecular phase ${ }^{[4]}$.

The simplest model describing the limited sorbing capacity of accumulated pollutants is presented by the Langmuir model. This model assumes that the surface of the adsorbent has a fixed number of active areas for adsorbing molecules and that each area can be filled by one molecule. The bond with the adsorbent may have a chemical or physical nature, but it must be strong enough, so that the adsorbed molecules do not move on the surface of the sorbent. According to the Langmuir isotherm, the amount of sorbed chemical is connected to the concentration in the aqueous phase by means of the following expression:

$\mathrm{q}=\left(\mathrm{S} \cdot \mathrm{b} \cdot \mathrm{C}_{\mathrm{e}}\right) /\left(1+\mathrm{b} \cdot \mathrm{C}_{\mathrm{e}}\right)$

Where:

$\mathrm{S}=$ The maximum capacity of sorption (fraction of occupied sites)

$\mathrm{b}$ = A parameter depending on energy, defining the interaction between the dissolved substance and the surface

$\mathrm{C}_{\mathrm{e}}=$ The concentration of the compound remaining in equilibrium in the solution

Langmuir theory relates to an ideal case, when the adsorption process occurs on an energetically homogeneous surface, without mutual interactions between molecules of the adsorbate ${ }^{[6,7]}$.
At present, the equation most often used to describe quantitatively the sorption equilibrium of HOCs onto soils and sediments is the Freundlich adsorption model:

$\mathrm{q}=\mathrm{K}_{\mathrm{f}} \cdot \mathrm{C}_{\mathrm{e}}^{\mathrm{n}}$

Where:

$\mathrm{C}_{\mathrm{e}}=$ The concentration of the chemical of concern in equilibrium in the liquid phase

$\mathrm{K}_{\mathrm{f}}=$ The diffusion coefficient that corresponds to a concrete adsorbent-adsorbate combination and defines the sorptive ability of the adsorbent

$\mathrm{n}=$ The Freundlich constant: It may be used as an index of the nonlinearity of the process

Freundlich isotherm is able to describe the adsorption process on heterogeneous surfaces (i.e., from an energetic point of view) and on surfaces of micro-porous adsorbents. This model is based on the assumptions that various types of active areas interact simultaneously and that they differ in both quantity and free enthalpy.

The afore mentioned adsorption models were combined in the distributed reactivity model developed by Weber and Coauthors ${ }^{[8]}$. This model takes into account the non-classical nature of the adsorption of HOCs by soils. In the distributed reactivity model the soil is considered as a composite material containing inorganic and two types of organic constituents, each of them characterized by its local sorption isotherm. The adsorption of organic contaminants on the exposed surface of the inorganic mineral components is described by the Langmuir isotherm. Another part of the soil constituent is the geologically-older hard organic fraction (kerogen, coals,...) that presents a relatively hydrophobic surface upon which the retention of the contaminant is described by the Freundlich isotherm. The other type of organic soil component is represented by the evolutionary immature soft material (humic substances) which are more likely to function as partitioning media upon which the retention of solute is characterized by a linear Henry-type of isotherm equation. The distributed reactivity model accommodates these linear and non-linear local adsorption isotherms and the total sorption phenomenon is approximated as the sum of the isotherms ${ }^{[8]}$.

In environmental chemistry the unknown equilibrium partition coefficients between two phases such as soil and water are frequently predicted using one-parameter Linear Free Energy Relationships (LFERs). In this context the term partitioning is used for any kind of distribution between different compartments, no matter whether these compartments 
are bulk phases (absorption) or interfaces (adsorption). In this model the partitioning of HOCs between water and natural phases is usually simply attributed to the hydrophobicity of each considered compound. The hydrophobicity is expressed by the octanol/water partition constant or the water solubility of the (subcooled) liquid compound. One parameter LFERs relate a know partition constant of each compound (log $\left.\mathrm{K}_{\mathrm{OW}}\right)$ to an unknown partition constant $\left(\log \mathrm{K}_{\mathrm{OM}}\right)$ in a linear double logarithmic correlation:

$\log \mathrm{K}_{\mathrm{OM}}=\mathrm{a} \cdot \log \mathrm{K}_{\mathrm{OW}}+\mathrm{b}$

$\mathrm{K}_{\mathrm{OM}}=\mathrm{K}_{\mathrm{D}} / \mathrm{f}_{\mathrm{OM}}$

This implies that the free energies of transfer of both partition processes (e.g., octanol/water and $\mathrm{SOM} /$ water) must be linearly related, hence the name LFER $^{[4]}$. In practice one-parameter LFERs have been used as an empirical tool without any considerations about the underlying linear free energy relationships.

Although useful in many contexts, being able to provide a good estimation of the equilibrium partition coefficient $\mathrm{K}_{\mathrm{D}}$ in soils with $\mathrm{f}_{\mathrm{OC}}>0.0025$, the partition model based on LFER theory is quite limited because no single parameter is able to describe appropriately all the molecular interactions that determine the equilibrium partitioning of a given compound between two phases ${ }^{[9]}$.

Standard laboratory batch sorption studies must be used to determine the distribution coefficient $\left(\mathrm{K}_{\mathrm{D}}\right)$ of a chemical compound between a soil/sediment and an aqueous phases in a more accurate way than models based on LFER theory.

\section{MATERIALS AND METHODS}

Reagents: Benzene, toluene, chlorobenzene, Trichloroethylene (TCE) and Perchloethylene (PCE) were all purchased from Sigma-Aldrich (Germany).

The physical-chemical parameters of the considered contaminants are shown in Table 1.

Characterization of the soil: The soil employed for the batch tests came from the mixing of three $2 \mathrm{~kg}$ samples collected at different depth values in a site near Florence (Italy). The three considered soil samples are representative of the unconfined aquifer.

Each soil sample was first air dried and, then, the particle-size distribution analysis was carried out on the sample resulting from the mixing.

Physical and chemical characterization and batch tests were performed on the soil fraction having dimension lower than $2 \mathrm{~mm}$. Physical and chemical characterization concerns the determination of the Total Organic Carbon (TOC), carbonate and metals content, Cation Exchange Capacity (CEC) and $\mathrm{pH}$ determination. The afore mentioned parameters were determined according to the methods shown in Bartles ${ }^{[11]}$.

Batch adsorption tests: Adsorption tests were performed in $250 \mathrm{~mL}$ glass vials, kept under continuous agitation $(250 \mathrm{rpm})$ on a multi-position orbital stirrer, supplied by VELP Scientifica (Italy). Temperature value was maintained at $20 \pm 1^{\circ} \mathrm{C}$.

Multi-contaminant adsorption tests were performed putting in contact $50 \mathrm{~g}$ of dried soil together with $200 \mathrm{~mL}$ of a contaminant solution (solid-liquid ratio 1:4 b.w., by weight). The contaminant solutions were obtained mixing weighted amounts of the considered pollutants with distilled water containing $1200 \mathrm{mg} \mathrm{L}^{-1}$ calcium chloride $\left(\mathrm{CaCl}_{2}\right)$ and $200 \mathrm{mg} \mathrm{L}^{-1} \mathrm{NaN}_{3}$ (as bioinhibitor). These solutions were characterized by a $\mathrm{pH}$ value equal to about 7 and an electric conductivity value equal to about $1.2 \mathrm{mS} \mathrm{cm}^{-1}$.

At the beginning of each batch test, the soil was placed into the bottles and the contaminant solution was then poured into the bottle and immediately sealed with a polypropylene screw cap fitted with Teflon-coated silicone septum. No headspace was left in the bottle and the bottle contents were only in contact with Teflon and glass.

The initial concentration for each contaminant is shown in Table 2. Concentration values are quite different among the tested compounds and represent the pollution level of the considered site well.

Vials were stirred for $72 \mathrm{~h}$ in order to achieve the equilibrium. After $72 \mathrm{~h}$, the samples of soil slurry were withdrawn and the two phases were separated by centrifugation. The supernatant was then analyzed, providing the equilibrium concentration of the contaminants of interest in the liquid phase. The concentration of the contaminants of interest in the solid phase (adsorbent) was determined taking advantage of a mass balance performed on each contaminant.

To take into account for any possible solute loss not due to the sorption onto the sorbent (i.e., sorption to septum and glassware and volatilization), the loss of the considered contaminants was measured and compared to control sample bottles that did not contain the solid.

The determination of the considered contaminants in the liquid phase after the equilibration, $\mathrm{C}_{\mathrm{e}}$, was carried out by means of headspace gaschromatography. 
Am. J. Environ. Sci., 5 (4): 508-516, 2009

Table 1: Physical-chemical parameters of the considered contaminants ${ }^{[10]}$

\begin{tabular}{|c|c|c|c|c|c|c|c|}
\hline Chemical & Formula & $\begin{array}{l}\text { Molecular weight } \\
\left(\mathrm{g} \mathrm{moL}^{-1}\right)\end{array}$ & $\begin{array}{l}\text { Vapor pressure } \\
25^{\circ} \mathrm{C}(\mathrm{mmHg})\end{array}$ & $\begin{array}{l}\text { Solubility in water } \\
25^{\circ} \mathrm{C}\left(\mathrm{mg} \mathrm{L}^{-1}\right)\end{array}$ & $\begin{array}{l}\text { Henry's constant } \\
\left(25^{\circ} \mathrm{C}\right)\left(\mathrm{Pa} \mathrm{m}^{3} \mathrm{moL}^{-1}\right)\end{array}$ & $\begin{array}{l}\text { Density } 25^{\circ} \mathrm{C} \\
\left(\mathrm{kg} \mathrm{dm}^{-3}\right)\end{array}$ & $\begin{array}{l}\log \mathrm{K}_{\text {ow }} \\
25^{\circ} \mathrm{C}\end{array}$ \\
\hline Benzene & $\mathrm{C}_{6} \mathrm{H}_{6}$ & 78,11 & 95 & 1800 & 548 & 0,874 & 2,13 \\
\hline Chlorobenzene & $\mathrm{ClC}_{6} \mathrm{H}_{5}$ & 112,56 & 12 & 490 & 390 & 1,101 & 2,80 \\
\hline PCE & $\mathrm{Cl}_{2} \mathrm{C}=\mathrm{CCl}_{2}$ & 165,83 & 20 & 200 & 1530 & 1,630 & 2,88 \\
\hline TCE & $\mathrm{HClC}=\mathrm{CCl}_{2}$ & 131,39 & 74 & 1100 & 910 & 1,460 & 2,53 \\
\hline Toluene & $\mathrm{CH}_{3} \mathrm{C}_{6} \mathrm{H}_{5}$ & 92,14 & 28 & 520 & 650 & 0,867 & 2,69 \\
\hline
\end{tabular}

Table 2: Initial concentration values for each contaminant

\begin{tabular}{lccccrr}
\hline Contaminant/series & $\mathrm{A}[\mathrm{ppb}]$ & $\mathrm{B}[\mathrm{ppb}]$ & $\mathrm{C}[\mathrm{ppb}]$ & $\mathrm{D}[\mathrm{ppb}]$ & $\mathrm{E}[\mathrm{ppb}]$ & $\mathrm{F}[\mathrm{ppb}]$ \\
\hline Benzene & 245 & 490 & 1400 & 2800 & $5600(*)$ & $8400(*)$ \\
Chlorobenzene & 440 & 880 & 1500 & 3000 & $6000(*)$ & $9000(*)$ \\
PCE & 185 & 370 & 600 & 1200 & $2400(*)$ & $3600(*)$ \\
TCE & 16 & 32 & 63 & 125 & $250(*)$ & $375(*)$ \\
Toluene & 9000 & 18000 & 45000 & 90000 & 180000 & 270000 \\
\hline
\end{tabular}

$(*)$ : Values not utilized in the isotherms evaluation

Benzene, chlorobenzene and toluene were analyzed by a gas chromatograph (GC) Agilent HP6890 equipped with FID-TCD (flame ionized detectorthermo-conductivity detector) detectors using a capillary column (HP-5, 5\% PH ME Siloxane, $30 \mathrm{~m} \times$ $0,32 \mathrm{~mm} \times 0,25 \mu \mathrm{m})$.

TCE and PCE were analyzed by a GC Agilent HP4890 with ECD (electron-capture detector) using a capillary column (HP-5, 5\% PH ME Siloxane, $15 \mathrm{~m} \times$ $0,53 \mathrm{~mm} \times 1,5 \mu \mathrm{m})$.

About $200 \mu \mathrm{L}$ headspace gas samples were introduced into the GCs.

The total amount of solute sorbed on each soil sample was evaluated from the difference in measured concentrations before and after equilibration, after adjusting for the volume of solution, $\mathrm{V}$ and the mass of soil, M. The final concentration into the soil after sorption, q, was then calculated from the expression:

$$
\mathrm{q}=\mathrm{V} / \mathrm{M}\left(\mathrm{C}_{0}-\mathrm{C}_{\mathrm{e}}\right)
$$

Where:

$\mathrm{C}_{0}=$ The effective initial concentration of solute in the aqueous phase obtained by subtracting volatilization losses estimated from the corresponding blank tests from the initial mass added

$\mathrm{C}_{\mathrm{e}}=$ The equilibrium concentration in the aqueous phase

\section{RESULTS}

The particle size distribution of the soil of concern is shown in Fig. 1.

As for the original soil sample, $80 \%$ b.w. of the particles is in the size range associated with sand and gravel and approximately $6 \% \mathrm{~b} . \mathrm{w}$. of the particles is in the size range associated with clay $(<2 \mu \mathrm{m})$.
Table 3: Physical-chemical parameters of the tested soil (fraction

\begin{tabular}{llll}
\multicolumn{1}{c}{$<2 \mathrm{~mm})$} & & & \\
\hline $\mathrm{pH}$ & 7,54 & $\mathrm{Na}\left(\mathrm{mg} \mathrm{kg}^{-1}\right)$ & 522 \\
$\mathrm{CaCO}(\%)$ & 19,8 & $\mathrm{Ba}\left(\mathrm{mg} \mathrm{kg}^{-1}\right)$ & 313 \\
$\mathrm{TOC}(\%)$ & 0,262 & $\mathrm{Ti}\left(\mathrm{mg} \mathrm{kg}^{-1}\right)$ & 295 \\
$\mathrm{CEC}(\mathrm{meq} / 100 \mathrm{~g})$ & 5,42 & $\mathrm{Cr}\left(\mathrm{mg} \mathrm{kg}^{-1}\right)$ & 37 \\
$\mathrm{Ca}(\%)$ & 8,40 & $\mathrm{Ni}\left(\mathrm{mg} \mathrm{kg}^{-1}\right)$ & 30 \\
$\mathrm{Fe}(\%)$ & 1,92 & $\mathrm{Cu}\left(\mathrm{mg} \mathrm{kg}^{-1}\right)$ & 14 \\
$\mathrm{Al}(\%)$ & 0,87 & $\mathrm{~Pb}\left(\mathrm{mg} \mathrm{kg}^{-1}\right)$ & 7,2 \\
$\mathrm{Mg}(\%)$ & 0,62 & $\mathrm{Co}\left(\mathrm{mg} \mathrm{kg}^{-1}\right)$ & $<1,2$ \\
$\mathrm{~K}(\%)$ & 0,46 & $\mathrm{Cd}\left(\mathrm{mg} \mathrm{kg}^{-1}\right)$ & $<0,40$ \\
$\mathrm{Mn}(\%)$ & 0,11 & $\mathrm{Zn}\left(\mathrm{mg} \mathrm{kg}^{-1}\right)$ & $<0,36$
\end{tabular}

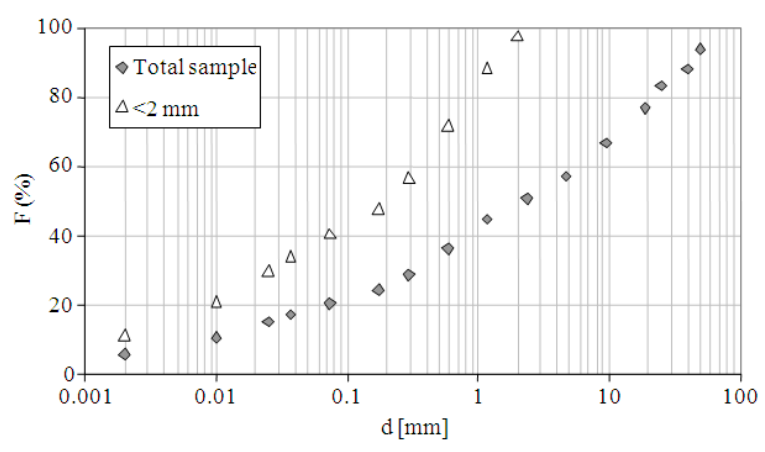

Fig. 1: Particle size distribution

As for the fraction having size $<2 \mathrm{~mm}, 63 \% \mathrm{~b}$.w. of the particles is in the size range associated with sand and approximately $12 \%$ b.w. of the particles is in the size range associated with clay $(<2 \mu \mathrm{m})$.

The results of the physical-chemical characterization of the considered soil are shown in Table 3. In particular, Table 3 reports TOC, carbonate and metal contents and $\mathrm{CEC}$ and $\mathrm{pH}$ values for the soil fraction having size $<2 \mathrm{~mm}$ on which batch tests have been carried out.

As shown in Table 3, the soil undergone the batch tests is characterized by about $20 \%$ b.w. of carbonates, low amounts of metal oxides (mainly, aluminum, iron 
Am. J. Environ. Sci., 5 (4): 508-516, 2009

Table 4: Fitted isotherm coefficients and correlation coefficient $\mathrm{R}^{2}$-in bold the best correlation coefficient for each contaminant

\begin{tabular}{|c|c|c|c|c|c|c|c|c|c|}
\hline & $\begin{array}{l}\text { Linear } \\
\mathrm{K}_{\mathrm{D}}\end{array}$ & $\begin{array}{l}\text { Freundlich } \\
\mathrm{R}^{2}\end{array}$ & $\begin{array}{l}\text { Langmuir } \\
\mathrm{K}_{\mathrm{F}}\end{array}$ & $\begin{array}{l}\text { LFER } \\
\mathrm{n}\end{array}$ & $\mathrm{R}^{2}$ & $\mathrm{~K}_{\mathrm{L}}$ & $\mathrm{C}_{\text {Smax }}$ & $\mathrm{R}^{2}$ & $\mathrm{~K}_{\mathrm{D}}$ \\
\hline Benzene & 0.723 & 0.972 & 0.249 & 1.130 & 0.968 & - & - & - & 0.142 \\
\hline Chlorobenzene & 1.298 & 0.913 & 3.130 & 0.889 & 0.920 & - & - & - & 0.819 \\
\hline TCE & 2.140 & 0.986 & 0.396 & 1.350 & 0.984 & - & - & - & 0.474 \\
\hline PCE & 3.840 & 0.979 & 5.990 & 0.935 & 0.978 & 0.00021 & 21584 & 0.977 & 0.963 \\
\hline Toluene & 0.465 & 0.949 & 4.210 & 0.824 & 0.957 & $1.9 \cdot 10^{-6}$ & 359308 & 0.960 & 0.520 \\
\hline
\end{tabular}

and manganese) and a very low content of organic carbon $(0.262 \%$ b.w. $)$; this value is very similar to the organic carbon content usually found in aquifer materials.

The data obtained in the series of batch tests were fitted with a number of sorption models: Linear (Henry), Freundlich, Langmuir and Langmuir-derived dual mode model (DMM).

Each of the five systems (one for each contaminant) contains from 10 (benzene, chlorobenzene, TCE and PCE) to 18 (toluene) experimental points.

The linear (Henry) isotherm $\mathrm{q}=\mathrm{K}_{\mathrm{D}} \cdot \mathrm{C}_{\mathrm{e}}$ was used in this study to interpret batch sorption experimental results.

It is possible to convert $\mathrm{K}_{\mathrm{D}}$ to $\mathrm{K}_{\mathrm{OC}}$ (distribution coefficient with the organic carbon) or to $\mathrm{K}_{\mathrm{OM}}$ (distribution coefficient with the organic matter) values by normalizing the $K_{D}$ value to the organic carbon $\left(f_{O C}\right)$ or the organic matter $\left(f_{O M}\right)$ content of the soil using the following equations:

$$
\mathrm{K}_{\mathrm{OC}}=\mathrm{K}_{\mathrm{D}} / \mathrm{f}_{\mathrm{OC}}
$$

or

$$
\mathrm{K}_{\mathrm{OM}}=\mathrm{K}_{\mathrm{D}} / \mathrm{f}_{\mathrm{OM}}
$$

The relation commonly utilized to bind the organic carbon content to the organic matter content is $\mathrm{f}_{\mathrm{OM}}=2 \cdot \mathrm{f}_{\mathrm{OC}}$, assuming that the organic matter in the soil is the principal reservoir responsible for the distribution between solids and water ${ }^{[4]}$.

Data coming from laboratory tests were in their turn fitted to the Freundlich model to obtain information about the nonlinearity degree of the sorption process. As previously mentioned, the equation of the Freundlich model is given by:

$$
\mathrm{q}=\mathrm{K}_{\mathrm{F}} \cdot \mathrm{C}^{\mathrm{n}}
$$

where, $\mathrm{K}_{\mathrm{F}}\left[\left(\mathrm{mg} \mathrm{kg}^{-1}\right) /\left(\mathrm{mg} \quad \mathrm{L}^{-1}\right)^{\mathrm{n}}\right]$ is the affinity coefficient and $\mathrm{n}$ is an exponential coefficient ${ }^{[12]}$.

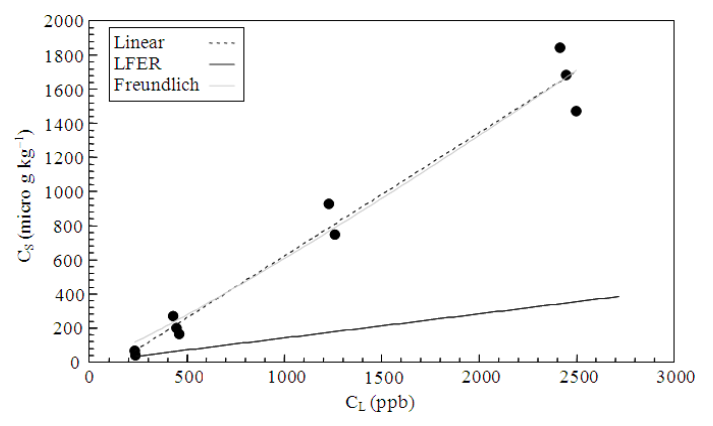

Fig. 2: Benzene-experimental points and isotherms

Experimental data were also fitted to the simple Langmuir model and, in the end, they were fitted to the Langmuir-derived Dual Mode Model (DMM) which includes a solid-phase dissolution (partitioning) described by a linear term (Henry) and a hole-filling described by a Langmuir term ${ }^{[12]}$. The DMM is given by:

$$
q=K_{D} \cdot C_{e}+\frac{S \cdot b \cdot C_{e}}{1+b \cdot C_{e}}
$$

The fitted coefficients for each type of isotherm are shown in Table 4 as well as the correlation coefficient $\mathrm{R}^{2}$.

Data obtained in the experimental tests are not suitable for the Langmuir fitting for benzene, chlorobenzene and trichloroethylene, so the fitted isotherms are not shown in Fig. 2-4 and the values are omitted from Table 4. Besides, the setting-up of DMM isotherms from the data obtained in the experimental tests failed for the all considered compounds.

The sorption isotherms for the contaminants of concern are presented in Fig. 2-6. On the basis of the $\mathrm{R}^{2}$ values shown in Table 4, both the linear model and the Freundlich model provide a good fit for the observed sorption data, over the tested concentration range, for benzene, chlorobenzene, TCE and PCE. On the other hand, the Langmuir model is the best for toluene experimental data, in fact toluene $\mathrm{R}^{2}$ value of the Langmuir model is better than those of Freundlich and linear models. 
Am. J. Environ. Sci., 5 (4): 508-516, 2009

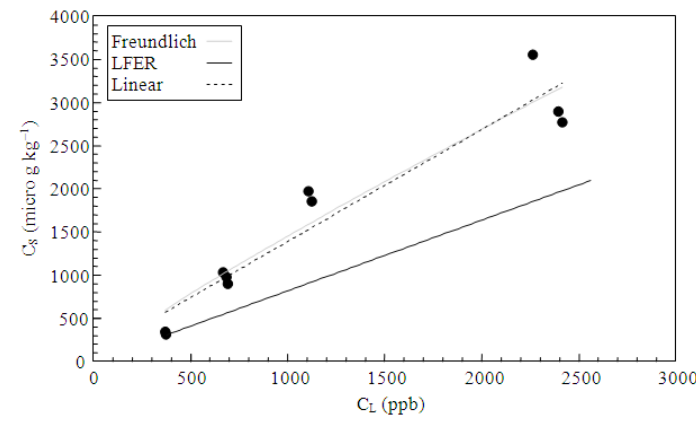

Fig. 3: Chlorobenzene-experimental points and isotherms

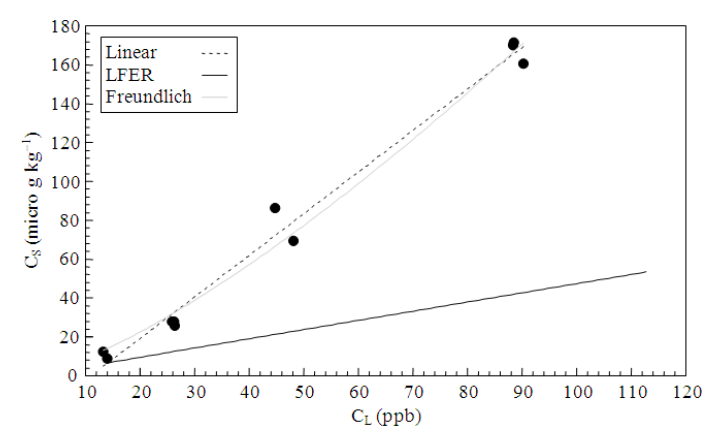

Fig. 4: TCE-experimental points and isotherms

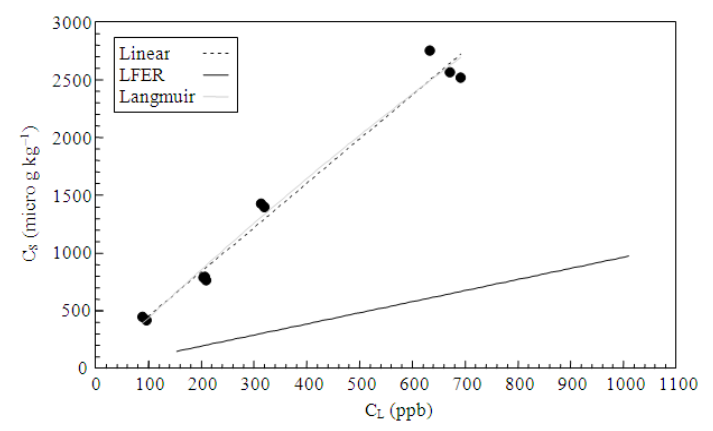

Fig. 5: PCE-experimental points and isotherms

In Fig. 7 the most adequate fits to the observed results (e.g., sorption models showing the highest correlation coefficient for each compound) for benzene, chlorobenzene and TCE were compared. This comparison was possible because the starting concentration ranges in the liquid phase for the three mentioned compounds nearly overlap (Table 2 ).

As mentioned above, the distribution coefficient $K_{D}$ can also be estimated from Eq. 5 and 6 according to LFER model. According to Schwarzenbach ${ }^{[4]}$ the $a$ and $b$ values for aromatic hydrocarbons (benzene and toluene) at $25^{\circ} \mathrm{C}$ are 1.01 and -0.72 , respectively and the $\mathrm{a}$ and $\mathrm{b}$ values for chlorinated hydrocarbons (chlorobenzene, TCE and PCE) are 0.88 and -0.27 , respectively.
Table 5: LFER model coefficients

\begin{tabular}{|c|c|c|c|c|c|c|c|}
\hline Com & $\mathrm{a}$ & $\mathrm{b}$ & $\mathrm{K}_{\mathrm{OW}}$ & $\begin{array}{l}\text { Log } \\
\mathrm{K}_{\mathrm{OW}}\end{array}$ & $\begin{array}{l}\text { Log } \\
\mathrm{K}_{\mathrm{OM}}\end{array}$ & $\mathrm{K}_{\mathrm{OM}}$ & $K_{D}$ \\
\hline $3 \mathrm{e}$ & & 0 & & 2.13 & 1.43 & 27 & , \\
\hline Chlo & 0.88 & -0.27 & 6 & 2.80 & 2.19 & 156 & 0.819 \\
\hline ГCE & 0.88 & -0.27 & 338 & 2.53 & 1.96 & 90.45 & 0.474 \\
\hline${ }^{\mathrm{C}} \mathrm{C}$ & 0.88 & -0.27 & 75 & 2.88 & 2.26 & 183.80 & 0.963 \\
\hline Toluene & 1.01 & -0.72 & 489.78 & 2.69 & 2.00 & 99.29 & 0.520 \\
\hline
\end{tabular}

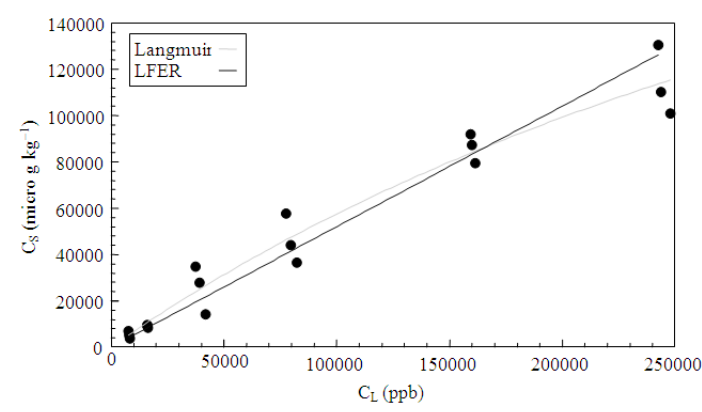

Fig. 6: Toluene-experimental points and isotherms

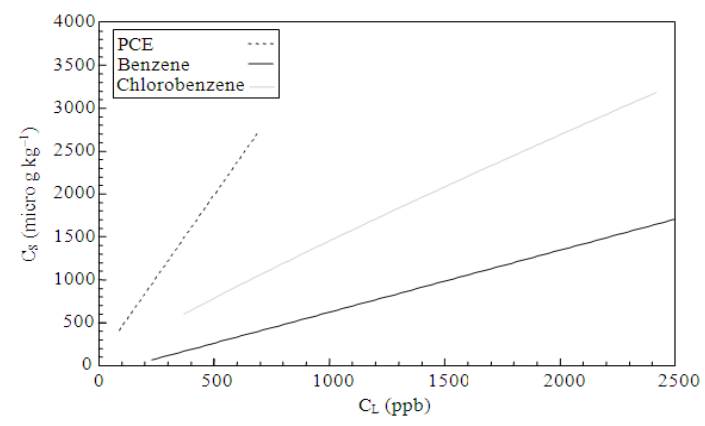

Fig. 7: Experimental isotherms-comparison

Known these parameters and the $\mathrm{K}_{\mathrm{OW}}$ values for the contaminants of concern (Table 1), it is possible to calculate $\mathrm{K}_{\mathrm{OM}}$ and, then, $\mathrm{K}_{\mathrm{D}}$ according to LFER model. The $K_{D}$ coefficients for the isotherms built in agreement with LFER model are shown in Table 5. The linear isotherms (Henry) obtained from the experimental data were compared with the isotherms estimated taking advantage of the LFER theory.The isotherms from Eq. 5 for the contaminant of concern are also shown in Fig. 2-6.

\section{DISCUSSION}

As regards the contaminants for which the best fit is done by the linear model (Table 4, benzene, TCE and PCE), the Henry coefficient, which describes the behavior of linear isotherms, accounts for the adsorption capacity of the soil at low to moderate 
concentrations. Accordingly, the following remarks can be made:

- $\quad \mathrm{PCE}$ is more strongly adsorbed than TCE, being the PCE Henry constant larger for about a two-fold factor

- In its turn, TCE is more strongly adsorbed than benzene, being the TCE Henry constant larger for about a three-fold factor

The higher sorption ability of the soil towards PCE, compared to the other contaminants tested over the same concentration range (benzene and chlorobenzene), may be ascribed to the higher PCE $\mathrm{K}_{\mathrm{OW}}$ coefficient, sign of a stronger affinity of this contaminant for the soil organic matter. Besides, PCE has a higher chlorination degree, responsible for a more intense electro-negativity, that makes the compound more capable to interact with the positively-charged sites.

It is well known that the adsorption of HOCs on soils is usually directly related to the organic carbon amount of the soil. However, it has been demonstrated $^{[13]}$ that, for each soil and for each chemical, exists a minimum amount of organic carbon $\left(f^{*}\right.$ OC) which discriminates if the sorption process is leaded by the partition with the organic carbon or related to other processes depending on the presence of charged-surface minerals. In soils in which $\mathrm{f}_{\mathrm{OC}}<\mathrm{f}^{*}{ }_{\mathrm{OC}}$ the phenomena of superficial interaction enter in competition with the organic carbon partition. Further to these remarks, the minimum fraction of organic carbon in which organic matter serves as the primary sorbent $\left(f^{*}{ }_{\text {OC }}\right)$ was determined. This quantity can be calculated as:

$\mathrm{f}^{*}{ }_{\mathrm{oC}}=\frac{\mathrm{S}_{\mathrm{a}}}{2\left(\mathrm{~K}_{\mathrm{OW}}\right)^{0.84}}$

Where:

$\mathrm{S}_{\mathrm{a}}=$ The soil surface area

$\mathrm{K}_{\mathrm{OW}}=$ The octanol-water partition coefficient for the contaminant of concern ${ }^{[13,14]}$

For the considered soil, the soil surface area has been calculated according to the formula ${ }^{[15]}$ :

$\mathrm{S}=\phi \cdot \frac{6}{\Delta} \cdot \sum \frac{\mathrm{f}}{\mathrm{d}_{\mathrm{s}}}$

Where:

$\mathrm{d}_{\mathrm{s}}=$ The effective diameter defined as a diameter of the sphere with the same volume as the average particle for a given size class $\mathrm{f}=$ The fraction of the sample mass within the given class

$\Delta=$ The density of the soil solid phase

The non-sphericity of the soil particles is taken into account by the factor $\phi$, which usually assumes values in the range between 1.3 and 2. The surface area resulting from Eq. 9 is traditionally called a geometric surface area, since it is believed that this assessment reflects a hypothetical smooth surface enveloping the actual soil particles ${ }^{[15]}$. The calculated surface area resulted equal to $0.55 \mathrm{~m}^{2} \mathrm{~g}^{-1}$, assuming $\Delta=2.65 \mathrm{~g} \mathrm{~cm}^{-3}$ and $\phi=1.75$.

By using equation 8 the $\mathrm{f}^{*}{ }_{\mathrm{OC}}$ for the different contaminants of concern have been calculated and the obtained values are shown in Table 6; all values are slightly below the measured organic carbon content of the soil, with the exception of benzene. It can then be inferred that, only for benzene, the organic matter serves as the primary sorbent, whereas the sorption of the other contaminants into the soil has to be probably referred to contending processes of both partition and superficial interactions. HOCs sorption dominated by partitioning results in linear (or nearly linear) isotherms and non-linear isotherms probably imply surface processes. In this context, the isotherm nonlinearity has been explained suggesting a possible mineral contribution to sorption. However, the good $\mathrm{R}^{2}$ values obtained for the all five systems fitted to linear isotherms (Henry) show that, in general, the sorption linear isotherms are able to describe the sorptive behavior of HOCs in a satisfactory way.

Figure 2-6 show that the linear LFER-based model isotherms uniformly underestimate sorption over the whole tested concentration range with the exception of toluene. In particular, LFER model underestimates the adsorption process till five times in the case of benzene. Analogous differences between the sorptive predicted behavior and the observed one has been noticed in other relatively low-carbon aquifer samples ${ }^{[16-18]}$. In the study carried out by ${ }^{[18]}$, the linear LFER-based model isotherms uniformly underestimate sorption over the low concentration range and overestimate over the high concentration range; however,

Table 6: $\mathrm{f}_{\mathrm{OC}}^{*}$ (threshold organic carbon content) and experimental $\mathrm{f}_{\mathrm{OC}}$ for the given soil

\begin{tabular}{ll}
\hline & $\mathrm{f}_{\text {OC }}^{*}$ \\
\hline Benzene & 0.0045 \\
Chlorobenzene & 0.0012 \\
TCE & 0.0021 \\
PCE & 0.0010 \\
Toluene & 0.0015 \\
Experimental & 0.0026 \\
\hline
\end{tabular}


in the study by Ma and Coauthors ${ }^{[18]}$, the equilibration aqueous concentrations vary from about $0-15 \mathrm{mg} \mathrm{L}^{-1}$ and the upper point of this concentration range is about ten times higher than the aqueous concentration values proposed in the present research. Besides, Allen-King and Coauthors ${ }^{[19]}$ have demonstrated that the strongest deviation of a real systems from the theoretical model (LFER) takes place when low aqueous contaminant concentrations (with values from near zero to about $1 \mathrm{mg} \mathrm{L}{ }^{-1}$ ) and low amounts of organic carbon/matter (mainly kerogen, carbon, soot and other carbonaceous materials having high surface area) in the soil solid phase exist together. The substantial difference between the estimated behavior and the real one for benzene and chlorobenzene (LFER underestimates five times the adsorption of benzene but less than twice the adsorption of chlorobenzene) may even be due to the unsuitability of the coefficients utilized for the estimation of the LFER $K_{D}$. Benzene LFER $K_{D}$ has been calculated from (5) taking advantage of the coefficients for the aromatic hydrocarbons (1.01 and -0.72) proposed by Schwarzenbach and Coauthors ${ }^{[4]}$. If these coefficients were replaced in (5) by the values proposed by $\mathrm{Xia}^{[19]}$, where $\mathrm{a}=0.97$ and $\mathrm{b}=0.12$, the distribution coefficient $\mathrm{K}_{\mathrm{D}}$ based on the LFER model for benzene would result to be equal to $0.231\left(\mathrm{~L} \mathrm{~kg}^{-1}\right)$, only three times lower than the distribution coefficient determined in the batch tests. As for chlorobenzene, the classification proposed by Schwarzenbach and Coauthors $^{[4]}$ may carry to an ambiguity, in fact, according to that, this compound could be classified either as an aromatic hydrocarbon or as a chlorinated hydrocarbon. If for the calculation of the distribution coefficient $K_{D}$ based on the LFER model the values proposed by $\mathrm{Xia}^{[19]}, \mathrm{a}=0.97$ and $\mathrm{b}=0.50$, were utilized, $\mathrm{K}_{\mathrm{D}}$ would result equal to $0.431\left(\mathrm{~L} \mathrm{~kg}^{-1}\right)$, a value three times lower than the distribution coefficient determined in batch tests.

These findings are in agree with the results of several experimental studies: Theoretical models like LFER are able to estimate the sorption ability of a soil in a range $2<\mathrm{K}_{\mathrm{D}}$ experimental/ $\mathrm{K}_{\mathrm{D}}$ theoretical $<5^{[19]}$. The important practical implication of these results is that the $\mathrm{K}_{\mathrm{D}}$ based on theoretical models like LFER may give a wrong sorption estimation in some relatively low $\mathrm{f}_{\mathrm{OC}}$ aquifers.

Only for toluene the LFER linear model fits the sorption data very well. The linear (Henry) distribution coefficient $\mathrm{K}_{\mathrm{D}}$ is very close to that obtained from LFER correlation over the tested concentration range: The difference between the two $\mathrm{K}_{\mathrm{D}}$ values is the smallest among the five tested contaminants. The good agreement between the LFER-based $\mathrm{K}_{\mathrm{D}}$ and the experimental one may be due to the very high aqueous concentrations (from about $10-270 \mathrm{mg} \mathrm{L}^{-1}$ ) tested for toluene: the most of the available coefficients to insert in expressions like (5) were obtained from tests carried out in the presence of aqueous concentration values quite close to the water saturation limits ${ }^{[19]}$.

\section{CONCLUSION}

The distribution coefficients $K_{D}$ between the soil and an aqueous phase for five hydrophobic organic pollutants (benzene, chlorobenzene, TCE, PCE and toluene) on an Italian soil characterized by a low organic carbon content $\left(f_{O C}=0.00262\right)$ have been determined by means of several series of batch tests.

The data obtained in the batch tests were fitted with a number of sorption models: Linear (Henry), Freundlich, Langmuir and Langmuir-derived Dual Mode Model (DMM).On the basis of the $\mathrm{R}^{2}$ values shown in Table 4, both the linear model and the Freundlich model provide a good fit for the observed sorption data, over the measured concentration range, for benzene, chlorobenzene, TCE and PCE; on the other hand, the Langmuir model is the best for toluene experimental data, in fact the $\mathrm{R}^{2}$ value of the Langmuir model is better than those of Freundlich and linear models.

The real distribution coefficients $K_{D}$ obtained fitting the experimental points with a Henry-type isotherm range from $0.465\left(\mathrm{~L} \mathrm{~kg}^{-1}\right)$ in the case of toluene to $3.84\left(\mathrm{~L} \mathrm{~kg}^{-1}\right)$ in the case of PCE.

The results of the sorption tests for the five considered contaminants suggest that the complexities of a sorption process are oversimplified if the distribution coefficients $\mathrm{K}_{\mathrm{D}}$ are determined on the grounds of a theoretical model like the LFER-based model, which simply takes into accounts for the hydrophobicity of the target compound, expressed by the octanol/water partition constant and the $\mathrm{f}_{\mathrm{OC}}$ of the soil. In fact, apart from the case of toluene, the solute amounts sorbed in a soil sample are well higher than the theoretical sorbed amount calculated on the basis of the LFER theory.

Besides, the distribution coefficients values obtained from the batch tests are able to take into account for the competitive effects among the different pollutants in the given system.

\section{REFERENCES}

1. Belfort, G., 1979. Selective adsorption of organic homologues onto activated carbon from dilute aqueous solutions. Solvophobic interaction approach and correlation of molar adsorptivity with physicochemical parameters. Environ. Sci. Technol., 13: 939-946. DOI: 10.1021/es60156a006 
2. Chiou, C.T., L.J. Peters and V.H. Freed, 1979. A physical concept of soil-water equilibria for nonionic organic compounds. Science, 206: 831-832. http://www.ncbi.nlm.nih.gov/pubmed/17820762

3. Chiou, C.T., P.E. Porter and D.W. Schmedding Freed, 1983. Partition equilibria of nonionic organic compounds between soil organic matter and water. Environ. Sci. Technol., 17: 227-231. DOI: 10.1021/es00110a009

4. Schwarzenbach, R.P., P.M. Gschwend and D. Imboden, 1993. Environmental Organic Chemistry. Wiley, New York, USA., 1st Edn., ISBN: 9780471839415, pp: 255-341.

5. Rao, B.H. and S.R. Asolekar, 2001. QSAR models to predict effect of ionic strength on sorption of chlorinated benzenes and phenols at sedimentwater interface. Water Res., 35: 3391-3401. http://cat.inist.fr/?aModele $=$ afficheN\&cpsidt $=1127$ 737

6. Mechlińska, A., M. Gdaniec-Pietryka, L. Wolska and J. Namieśnik, 2009. Evolution of models for sorption of PAHs and PCBs on geosorbents. Trends Anal. Chem., 28: 466-482. DOI: 10.1016/j.trac.2009.01.005

7. Huang, W., P. Peng, Z. Yu and J. Fu, 2003. Effects of organic matter heterogeneity on sorption and desorption of organic contaminants by soils and sediments. Applied Geochem., 18: 955-972. http://cat.inist.fr/?aModele $=$ afficheN\&cpsidt $=1484$ 2865

8. Weber, Jr. W.J., P.M. Mc Ginley and L.E. Katz, 1992. Distributed reactivity model for sorption by soils and sediments. Environ. Sci. Technol., 26: 1955-1962.

http://direct.bl.uk/bld/PlaceOrder.do?UIN=000140 $351 \&$ ETOC $=$ EN\&from $=$ searchengine

9. Goss, K.U. and R.P. Schwarzenbach, 2001. Linear free energy relationships used to evaluate equilibrium partitioning of organic compoundscritical review. Environ. Sci. Technol., 35: 1-9. http://cat.inist.fr/?aModele $=$ afficheN\&cpsidt $=8516$ 06

10. Montgomery, J.H., 1996. Groundwater Chemicals. CRC Press, New York, 2nd Edn., ISBN: 9781566701655, pp: 1345.

11. Bartles, J.M., 1996. Methods of Soil Analysis, Part 3, Chemical Methods, Ed. Soil Science Society of America, Madison, Wisconsin, ISBN: 9780891188254, pp: 1264.
12. He, Y., J. Xu, H. Wang, Z. Ma and J. Chen, 2006. Detailed sorption of pentachlorophenol on soils and its correlation with soil properties. Environ. Res., 101: 362-372. DOI: 10.1016/j.envres.2006.01.002

13. Watts R.J., 1998. Hazardous Wastes: Sources, Pathways, Receptors. J. Wiley and Sons, ISBN: 10: 0471002380 , pp: 764.

14. Baciocchi, R., M.R. Boni and R. Lavecchia, 2005. Modeling of chlorophenols competitive adsorption on soils by means of the ideal adsorbed solution theory. J. Hazard. Mater., B118: 239-246. http://www.ncbi.nlm.nih.gov/pubmed/15721549

15. Koptsik, S., L. Strand and N. Clarke, 2003. On the calculation of the surface area of different soil size fractions. Applied Geochem., 18: 629-651. http://cat.inist.fr/?aModele $=$ afficheN\&cpsidt $=1467$ 3631

16. Allen-King, R.M., H. Groenevelt, C.J. Warren and D.M. Mackay, 1996. Non-linear chlorinatedsolvent sorption in four aquitards. J. Contam. Hydrol., 22: 203-221. http://cat.inist.fr/?aModele $=$ afficheN\&cpsidt $=3082$ 165

17. Benkler, E., G.B. Davis and D.A. Barry, 1998. Estimating the retardation coefficient of trichloroethene for a sand aquifer low in sediment organic carbon-a comparison of methods. J. Contam. Hydrol., 30: 157-178. http://infoscience.epfl.ch/record/63460

18. Ma, C., Y. Wu, C. Sun and L. Lee, 2007. Adsorption characteristics of perchloroethylene in natural sandy materials with low organic carbon content. Environ. Geol., 52: 1511-1519. http://cat.inist.fr/?aModele $=$ afficheN\&cpsidt $=1895$ 9127

19. Allen-King, R.M., P. Grathwohl and W.P. Ball, 2002. New modeling paradigms for the sorption of hydrophobic organic chemicals to heterogeneous carbonaceous matter in soils, sediments and rocks. Adv. Water Resour., 25: 985-1016. DOI: 10.1016/S0309-1708(02)00045-3 